\title{
scripted
}

Volume 15, Issue 1, August 2018

\section{Biobank Governance: The Cautionary Tale of Taiwan Biobank}

\author{
Shawn H.E. Harmon, * Shang-Yung Yen, ${ }^{* *}$ Shu-Mei Tang*** \\ (ㄷ) (i) $\Theta$ \\ (C) 2018 Shawn H.E. Harmon, Shang-Yung Yen, Shu-Mei Tang \\ Licensed under a Creative Commons Attribution-NonCommercial- \\ NoDerivatives 4.0 International (CC BY-NC-ND 4.0) license
}

DOI: $10.2966 /$ scrip.150118.103

\begin{abstract}
The importance of biobanks has long been mooted, and multiple models of development and operation can be found as a result of many actors founding biobanks (from institutions starting disease-specific banks to governments starting national population biobanks). Many countries began developing biobanks in the absence of national policies to aid in that formation. Taiwan was one such country. Believing that the unique genetic makeup, distinctive lifestyles, and disease-causing factors of the Taiwanese people deserved study, Taiwan took steps to create Taiwan Biobank. This paper examines Taiwan Biobank's development and governance and focuses on two matters in particular which generated consternation during the development of Taiwan Biobank: the position adopted in relation to autonomy and ethnicity; and the approach toward transparency and internal governance. It concludes that Taiwan Biobank's conflict-ridden evolution represents a cautionary tale, an example of how not to develop a flagship resource.
\end{abstract}




\section{Keywords}

Taiwan Biobank, governance, regulation, participation, ethnicity, consent, privacy

* Honorary Fellow, University of Edinburgh, and Adjunct Professor, Dalhousie University; Deputy Director, J Kenyon Mason Institute for Medicine, Life Sciences and Law

** Professor of Graduate Institute of Management of Technology, Feng Chia University, Taiwan

*** Professor, Financial \& Economic Law, Asia University, Taiwan 


\section{Introduction}

Shortly after the sequencing of the human genome, it was claimed that medical knowledge would be accelerated by the formation of 'biobanks', ${ }^{1}$ here defined as new repositories of human tissue and generated data (genetic, phenotypic, lifestyle, environmental, and demographic) together with associated health data (occupation, lifestyle, diet, and medical), which repositories are collective, inclusive, prospective, and purposively indeterminate. ${ }^{2}$ It was felt that largescale longitudinal investigations into the interaction between common disease genes and environmental factors would be an optimal way to overcome common diseases and improve health. ${ }^{3}$

Therefore, many countries began developing national policies to aid in the formation of biobanks, or began developing biobanks in the absence of policies. ${ }^{4}$ Taiwan fell into the latter category. Believing that the unique genetic makeup, distinctive lifestyles, and disease-causing factors of the Taiwanese people deserved specific study, ${ }^{5}$ Taiwan took steps to create a national biobank.

1 Brigitte Nerlich, Robert Dingwall, and David Clarke, "The Book of Life: How the Completion of the Human Genome Project was Revealed to the Public" (2002) 6 Health 445469; Bernice Elger and Arthur Caplan, "Consent and Anonymization in Research Involving Biobanks" (2006) 7 EMBO Reports 661-666.

2 Shawn Harmon, "Semantic, Pedantic or Paradigm Shift? Recruitment, Retention and Property in Modern Population Biobanking" (2008) 16 European J Health Law 27-43.

3 Jonathan Marchini et al., "The Effects of Human Population Structure on Large Genetic Association Studies" (2004) 36 Nature Genetics 512-517.

4 Jocelyn Kaiser, "Population Databases Boom: From Iceland to the US" (2002) 298 Science 1158-1161.

5 Elio Riboli et al., "European Prospective Investigation into Cancer and Nutrition (EPIC): Study Populations and Data Collection" (2002) 5 Pubic Health Nutrition 1113-1124; Chien-Te Fan, Jui-Chu Lin and Chung-His Lee, "Taiwan Biobank: A Project Aiming to Aid Taiwan's Transition into a Biomedical Island" (2008) 9 Pharmacogenomics 235-246; Chen-Yang Shen, "Taiwan Biobank and Its Purposes" (2010) 4 (4) Law \& Life Science 1-6; Akiko Nagai et al., "Overview of the BioBank Japan Project: Study Design and Profile" (2017) 27 (3) Journal of Epidemiology S2-S8; Chien-Te Fan, Tzu-Hsun Hung, and Chan-Kun Yeh, "Taiwan Regulation of Biobanks" (2015) 43 Journal of Law, Medicine \& Ethics 816-826. 
Proponents considered that, if the genes involved in common diseases could be defined and their risk quantified, new and improved treatments could be developed for Taiwan. Like many such banks, then, Taiwan Biobank's conception was an exercise in promise; a leap into the scientific and policy unknown supported by claims that risks would be offset by advances in health and by valuable collaborations and commercial returns, the latter of which was not always clearly conveyed to or understood by the public. ${ }^{6}$

This paper examines the establishment, development, and governance of Taiwan Biobank. First, it reviews the historical evolution of Taiwan Biobank. Secondly, it examines two areas that generated significant controversy in this evolution, namely, positions adopted in relation to autonomy and ethnicity, and approaches in relation to transparency and internal governance. We propose that Taiwan Biobank's problematic evolution represents a cautionary tale, highlighting pitfalls to avoid in developing a national flagship resource.

\section{The Development of Taiwan Biobank}

\subsection{Biotechnology in the Innovation Agenda (1990s-2005)}

Like many countries, Taiwan adopted a policy of sci-tech innovation as a means of achieving sustainable development and international competitiveness. Health technology innovation and the establishment of biobank infrastructure resources featured heavily in this policy:

6 Jon Merz, Glenn McGee, and Pamela Sankar, "'Iceland Inc.'?: On the ethics of commercial population genomics" (2004) 58 Social Science \& Medicine 1201-1209.

7 Kuei-Tien Chou, "Conflicts of Technology Policy and Governance Paradigm in a Knowledge-Based Economy: A Case Analysis of the Construction of the Taiwan Biobank" (2007) 43 Issues \& Studies 97-130. 
- 1997: The Science and Technology Advisory Group (STAG) of the Executive Yuan held its first strategic review meeting on biotech policy, intending to promote national projects in genetic medicine and public health technology. Consequent projects included the National Genetic Medicine and the National Pharmacy and Biotech Projects.

- 1998: A second strategic review meeting resulted in the National Development Fund investing NT\$20 billion to support the development of the biotech industry, the emphasis being on technology innovation projects, strategic alliances, and enterprise creation, including the investment by state-owned enterprises in the biotech industry.

- 1999: The Luchu Science Park was redeveloped with a Biomedicine District.

- 2001: Multiple regional 'Biotech Hallways' were created.

- 2002: The Academia Sinica established the Taiwan Han Chinese Cell and Genome Bank Project, which relied on data collected randomly through the computerised household registration system. ${ }^{8}$

- 2004: The STAG argued that Taiwan should become an 'island of biomedical technology', and made a number of related recommendations. ${ }^{9}$

In response to the STAG, the Taiwanese Government launched the Biomedical Technology Island Plan 2005, 10 which comprised three main projects: the

8 Editorial, "Academic Meeting Passed Genetic Establishment: Experts Consultation" (United Evening News, 4 July 2000); Yuan-Tsong Chen, "Super Task: Disease Genetic Decoding Project - Everyone Together" (China Times, 27 July 2003).

9 STAG, Policy Statement on Constructing an Island of Biomedical Technology (2004).

10 Taiwan Ministry of Economic Affairs, Report: Biomedical Technology Island Plan to Spur Investments of NT\$40 Billion over 5 Years (2005). 
National Health Information Infrastructure Project; the Taiwan Clinical Services Project; and Taiwan Biobank. With respect to the latter, the National Science Council (NSC), predecessor to the Ministry of Science and Technology, asked Academia Sinica's Institute of Biomedical Sciences (IBS) to plan a large-scale population biobank that would support biotechnology development and medical research in Taiwan. ${ }^{11}$

Adopting UK Biobank as its model, the IBS conceived of Taiwan Biobank, which would collect biological samples (blood, plasma, urine, and tissue) from some 200,000 healthy participants aged 30-70, and link those samples/data with their lifestyle, family history, and health information in an effort to determine the effects of genetic and environmental factors and interactions on common diseases, and to develop personalised medicine. ${ }^{12}$ Objectives included: determining the prevalence of specific genes and variations in the population; simplifying the procedure for searching for biological marker molecules; improving research into new curative medicines (especially for Taiwanprevalent diseases); and simplifying disease-prevention and improving public health and hygiene decisions. ${ }^{13}$ Importantly, both Taiwan Biobank and its Pilot

11 Don Chalmers et al., "Has the Biobank Bubble Burst? Withstanding the Challenges for Sustainable Biobanking in the Digital Era' (2016) 17 BMC Medical Ethics 39.

12 Yuan-Tsong Chen, Report: The Cohort Study of the Establishment of Taiwan Biobank and the Multiple Risk Factors for Multiple Diseases (National Science Council: NSC 94-3112-B-001-017, 2007); Yuan-Tsong Chen, Chen-Yang Shen et al, Report: The Preliminary Project of the Establish of Taiwan Biobank (Department of Health: DOH95-TD-M-113-B001, 2006); Yuan-Tsong Chen and Chen-Yang Shen, "Be Careful in Designing Biobank" (China Times, 2 April 2006).

13 Chia-Hao Ou and Chen-Yang Shen, "The Taiwan Biobank Project: For the Health of Future Generations" (2006) Academia Sinica E-News No. 12; Huan-Cheng Chang et al., "Biological Risk Factors Relevant to Chronic Disease in Three Ethnic Groups in Taiwan: Results from LiShin Outreaching Neighbourhood Screening" (2008) 18 Ethnicity \& Disease 228-234; ChinHsiao Tseng, "The ethnicity of Hakka Is associated with a Higher Risk of Hypertension Than Fukienese in Taiwanese Type 2 Diabetic Patients" (2008) 22 Journal of Human Hypertension 370-372; Hsin-Wen Lai et al., "Ethnic-specific Prevalence of Hepatitis B/C Virus Infection in Pin-Jen, Taiwan' (2009) 19 Ethnicity \& Disease 384-389. 
Study was structured around ethnicity; ${ }^{14}$ it aimed to build the resource by collecting samples from four target groups - the Hakka, ${ }^{15}$ the Minnan, ${ }^{16}$ the Han, ${ }^{17}$ and Aboriginals. ${ }^{18}$

\subsection{Controversy and ethnicity during the Pilot Study (2003-2007)}

Prior to commencement, Academia Sinica was tasked with performing a Pilot Study to test the scientific/technical feasibility of Taiwan Biobank. It had a target of 1,000 participants from three geographic regions: Miaoli (primarily Hakka); Chiayi (primarily Minnan); and Hualien (primarily Aboriginal). The ethnic foundation for the Pilot Study was not accompanied by any detailed or openlydiscussed or accepted definition of each group, nor indeed by any explanation as

14 Chou, supra n. 7. The intention to create a "racial genetic database" like that in Iceland is reported.

15 The Hakka is an immigrant group from Guangdong, Mainland China. They arrived in Taiwan in the late Ming and early Qing dynasties. See Hsin-Huang Hsiao and Khay Thiong Lim, "The Formation and Limitation of Hakka Identity in Southeast Asia" (2007) 4 Taiwan Journal of Southeast Asian Studies 3-28; Fu-Chang Wang, 'The Evolution of Attitude Toward Ethnic Categories and Assimilation in Taiwan', presented at the Annual Conference of Taiwanese Sociological Association, Taiwan, Academia Sinica, 2008. Changing ethnic classifications and rising inter-ethnic marriage have resulted in the Hakka making up approximately $13.5 \%$ of the Taiwanese population: Yu-yueh Tsai, "Geneticizing Ethnicity: A Study on the Taiwan Bio-Bank" (2010) 4 East Asian Science, Technology E Society 433-455.

16 The Minnan is an immigrant group from Fujian, Mainland China. They arrived in Taiwan in the late Ming and early Qing dynasties, and, according to the national Hakka Committee, the Minnan constitute approximately $67.5 \%$ of the Taiwanese population: Hakka Committee of Executive Yuan, Report on the National Population-Based Survey (2010-2011), available at http://www.hakka.gov.tw/dl.asp?fileName=1521131271.pdf (accessed 20 November 2014).

17 The Han are immigrants who fled from Mainland China in the mid-20th century.

18 The Aboriginals are Taiwan's earliest inhabitants. In the last four centuries, they have been forced into the mountainous and less developed eastern regions of the island. In addition to having socio-cultural structures and living habits that are generally distinct from the Handominated mainstream, their epidemiological history and biological traits are seen as unique. 
to what or who counted as Aboriginal. ${ }^{19}$ Nonetheless, the Pilot Study Protocol was approved by Academia Sinica's Institutional Review Board (IRB) in 2005.

The process leading up to (and beyond) this approval has been described as a 'development-first' approach with decisions being made almost exclusively by policy and science elites in closed processes..$^{20}$ Moreover, these decisions were sometimes based on misinterpretations of the course adopted in other countries, and they persistently exemplified either simplistic understandings of risk, or a complete disregard for the associated risks. ${ }^{21}$ And while there was some effort to encourage scientific discourses, there was no effort to be transparent or to undertake any public engagement. Indeed, it has been argued that the complexity of the project together with the exclusivity of its development hindered both public understanding and public debate. ${ }^{22}$ In short, there was no interest in social supervision.

19 It is no simple task to identify indigenous Taiwanese, or to differentiate them in medically meaningful ways from other historic communities, a difficulty compounded by the fact that people frequently identify with, and claim membership in, more than one social group. A 2004 survey demonstrated that, when presented with multiple choices, $73.3 \%$ of respondents self-identified as Minnan Han, $13.5 \%$ as Hakka Han, $8.0 \%$ as Mainlander Han, $1.9 \%$ as Aboriginals, and 3.3\% as Taiwanese: Hakka Committee of Executive Yuan, Report on the National Population-Based Survey (2004). In a 2010-2011 survey, $67.5 \%$ of respondents selfidentified as Minnan Han, $13.6 \%$ as Hakka Han, $7.1 \%$ as Mainlander Han, $1.8 \%$ as Aboriginals, and $7.5 \%$ as Taiwanese: Hakka Committee of Executive Yuan, Report on the National Population-Based Survey (2011). In the most recent survey, $66.4 \%$ of respondents selfidentified as Minnan Han, $13.5 \%$ as Hakka Han, $7.0 \%$ as Mainlander Han, $1.8 \%$ as Aboriginals, and $8.3 \%$ as Taiwanese: Hakka Committee of Executive Yuan, Report on the National Population-Based Survey (2014).

20 Chou, supra n. 7.

21 Hung-En Liu, "Legislative Policy Criticisms and Analyses of Icelandic Civil Medical and Genetic Database Establishment" (2004) 54 Taipei University Law Review 45-99; Hung-En Liu, "Public Trust, Commercialization, and Benefit Sharing in Biobanking" (2005) 57 Taipei University Law Review 367-368.

22 Chou, supra n. 7; Ching-Yi Liu, "How Come There Is a Taiwan Biobank?” (Judicial Reform Foundation, 15 February 2006), available at https://www.jrf.org.tw/newjrf/index new2014.asp?id=793 (accessed 2 August 2018). 
Eventually, and primarily after the academic community began to complain, the Pilot Study met with a maelstrom of public criticism, exemplified by a commentary in the China Times which raised questions about consent, confidentiality, and benefit-sharing, and which demanded that the plans for Taiwan Biobank be made public. ${ }^{23}$ One of the issues that was persistently raised was that of ethnicity. Given the poor record of Aboriginal treatment, the fragility of human subject protections, the circulation of stories about failures to meet consent standards, ${ }^{24}$ and the general absence of benefit-sharing models in Taiwan, ${ }^{25}$ the Taiwan Association for Human Rights made a formal request (in

23 Liu, supra $n$. 22. This publication was book-ended by academic criticism of the policymaking process leading to the conception of Taiwan Biobank: Hung-En Liu, "Legislative Policy Criticisms and Analysis of Icelandic Civil Medical and Genetic Database Establishment" (2004) 54 Taipei University Law Review 45-99; Kuei-Tien Chou, "Biomedtech Island Project and Risk Governance: Paradigm Conflicts within a Hidden and Delayed High-Tech Risk Society" (2007) 58 Soziale Welt 123-143. With respect to other grounds of concern, previous and ongoing incidents served to erode public trust; confidential personal information had been leaked by/from a number of information-holders to a variety of inappropriate parties, some of whom used it to commit fraud: Taiwan Association of Human Rights, "Personal Information Divulgence Cases of 2002" (2002), available at https://www.tahr.org.tw/news/87 (accessed 2 August 2018). And a new law requiring citizens to provide fingerprints before renewing their national ID cards was controversially passed, and then subsequently declared unconstitutional as an infringement of informational privacy: Judicial Yuan Interpretation No. 603.

24 Many were expressed, but note: Chao-Chun Wang, "Taiwan Biobank Blood Sampling Without Permission? Taiwan Association for Human Rights Calls for a Stop" (China Times, 23 January 2006); Zong-You Lee, “Doubts Over Human Rights Violations Remain: Taiwan Biobank Project Suck" (China Times, 24 July 2006); Chao-Chun Wang, “No One Understood the Reason for Blood Sampling in the Tribe" (China Times, 23 January 2006); Chao-Chun Wang, Chao-Chun Wang, et al " Academic Sinica Might Pry 200,000 Participants Through Blood Sampling" (China Times, 23 January 2006). They addressed a number of ethical issues.

25 It took some time before researchers even acknowledged the contribution that indigenous peoples have made to research. Eventually, the propriety (and difficulty) of benefiting indigenous peoples has been noted, and a range of international instruments have been adopted to facilitate more equitable treatment: Francesco Mauro and Preston Hardison, "Traditional Knowledge of Indigenous and Local Communities: International Debate and Policy Initiatives" (2002) 10 Ecological Applications 1263-1269. Intellectual developments on this issue have progressed largely in tandem with work around engagement: Katy Moran, 
July 2006) that Academia Sinica publish its project processes online so as to improve transparency. ${ }^{26}$ That request was refused, ${ }^{27}$ and the Pilot Study continued unabated. ${ }^{28}$

\subsection{Law-making, further controversy and recruitment (2007-2023)}

By 2007, and despite social outcry and non-engagement with social and ethical matters, the Pilot Study was viewed as having demonstrated feasibility. Thus, the Ministry of Health and Welfare (MOHW) directed the IBS to commence a Preparatory Study which would recruit 15,000 participants aged 30-70. The Preparatory Study dropped the overt emphasis on ethnic groups, but focused on Hakka, Minnan, and Aboriginal regions for its recruitment. As the study progressed, the number of participants was reduced to 8,000. During this time, the Executive Yuan took steps to legislate in the biobank setting so as to bring its regulatory environment more in line with international standards, adopting the Human Biobank Management Act 2010 (HBMA 2010), ${ }^{29}$ amending the Personal

"Bioprospecting: Lessons from Benefit-Sharing Experiences" (2000) 2 International Journal of Biotechnology 132-144; Paul Cox, "Ensuring Equitable Benefits: The Falealupo Covenant and the Isolation of Anti-Viral Drug Prostratin from a Samoan Medicinal Plant" (2001) 39 Pharmaceutical Biology 33-40. The potential of modern intellectual property systems to recognise and value indigenous contributions has been questioned: Dora Marinova and Margaret Raven, "Indigenous Knowledge and Intellectual Property: A Sustainability Agenda" (2006) 20 Journal of Economic Surveys 587-605.

26 Lee, supra n. 24.

27 Chou, supra n. 7.

28 The Pilot Study was tasked with conducting a test of the scientific/technical feasibility of Taiwan Biobank, but it failed to properly consult or authentically engage with the public, including the ethnic communities in Taiwan. See Shu-Mei Tang, "The Disputes of Establishing Taiwan Biobank" (2011) The Legal Risk of the Emerging Biotechnology 443-493.

29 See http://law.moj.gov.tw/Eng/LawClass/LawAll.aspx?PCode=L0020164. 
Information Protection Act 2010, ${ }^{30}$ and adopting the Human Subjects Research Act 2011 (HSRA 2011), ${ }^{31}$ more on which infra.

In October 2012, Taiwan Biobank was formally approved by Academia Sinica's IRB with the aims of preventing, diagnosing and treating a wide range of serious and life-threatening common complex diseases suffered by the Taiwanese people. ${ }^{32}$ Country-wide recruitment commenced in late 2012, and over 77,000 participants have thus far provided $30 \mathrm{ml}$ of blood, $20 \mathrm{ml}$ of urine, specified physical measures, detailed information about themselves, and have agreed to have their health followed..$^{33}$

In accordance with Article 5 of the HBMA 2010, Taiwan Biobank established an Ethics and Governance Council (EGC) to act as an independent guardian of Taiwan Biobank's Ethics and Governance Framework, and to advise the Competent Authority (the MOHW) on its revision from time to time. Very early in the EGC's existence, however, Taiwan Biobank took steps to amend its Protocol so that, in addition to the 200,000 participants originally envisioned, it could collect 100,000 patient samples and data from Taiwan's major hospitals, and it could focus on some specifically identified conditions (e.g., breast, lung, liver, colon, and rectum cancers, strokes, chronic kidney diseases, and Alzheimer's Disease). ${ }^{34}$ This amendment was approved post facto by the EGC (in

30 See http://law.moj.gov.tw/Eng/LawClass/LawAll.aspx?PCode=I0050021.

31 See http://law.moj.gov.tw/Eng/LawClass/LawAll.aspx?PCode=L0020176.

32 Lilian $\mathrm{Wu}$, "Taiwan Biobank helping develop therapies suitable to Taiwanese", (Focus Taiwan, 3 November 2015), available at http://focustaiwan.tw/news/asoc/201511030010.aspx (accessed 31 May 2017).

33 Taiwan Biobank, available at https://www.twbiobank.org.tw/new web/index.php.

$34 \mathrm{Wu}$, supra $\mathrm{n} .32$. 
2012). ${ }^{35}$ In early 2015, the MOHW recommended that hospitals share their banked resources with Taiwan Biobank. ${ }^{36}$

However, on 30 September 2016, Academia Sinica's IRB, which has authority to suspend or terminate any research that is not conducted in accordance with its requirements, or that has been associated with unexpected serious harm to subjects, held that it must approve any amendment to the Taiwan Biobank Protocol prior to its implementation. It therefore suspended Taiwan Biobank activities in response to this self-initiated inclusion of hospitals, ${ }^{37}$ holding that Taiwan Biobank should be governed by the EGC and the IRB jointly, with the EGC responsible for 'management' and the IRB responsible for 'research'. ${ }^{38}$ Taiwan Biobank responded that the EGC, not the IRB, is the main ethical governance structure for Taiwan Biobank. ${ }^{39}$ The MOHW countered that the Protocol should be submitted to and confirmed by the MOHW, which is the Competent Authority under the HBMA 2010.40

35 EGC, Report on Taiwan Biobank, 19 March 2012.

36 Editorial, "Taiwan Biobank Illegal Collection of Disease Specimens" (Next Magazine, 16 November 2016), available at https://www.nextmag.com.tw/realtimenews/news/45889342 (accessed 2 August 2018).

37 IRB, "Report on Application No. AS-IRB01-AS-IRB01-12017" (2016), available at http://irb.sinica.edu.tw/doc/bm/doc/passed/12017O1.pdf (accessed 31 May 2017).

38 IRB, "News", available at http://irb.sinica.edu.tw/doc/20161209IRBBM clarification.pdf (accessed 31 May 2017). It argued that, under the Human Subjects Research Act 2011, research involves obtaining, investigating, analysing, or using human specimens or an individual person's biological, physiological, psychological, behavioural, genetic, or medical information. Prior to conducting research, the Principal Investigator must submit the protocol for review and approval by the IRB. Amendments of an approved protocol must also be submitted for IRB approval prior to implementation. The IRB has authority to suspend or terminate research that is not being conducted in accordance with its requirements.

39 Taiwan Biobank, "News", available at https://www.twbiobank.org.tw/new web/index.php (accessed 31 May 2017).

40 Editorial, "The Disputes of Academia Sinica and the Taiwan Biobank”, (China Times, 16 November 2016), available at http://www.chinatimes.com/realtimenews/20161116001735$\underline{260405}$ (accessed 31 May 2017). 
This dispute re-ignited criticism from a range of stakeholders, including the Taiwan Association for Human Rights, ${ }^{41}$ and led to delays in operations. While the jurisdictional conflict has not been resolved, the IRB did issue a Certificate of Approval on 2 March 2017, which states that (1) annual progress reports should be submitted to the IRB for review, (2) progress reports submitted to the MOHW should be copied to the IRB, and (3) all adverse events must be reported promptly to the IRB. This Certificate also seems to have approved the amendments to the Protocol, opening the way for hospitals to transfer their holdings to Taiwan Biobank.

This rather tortured history highlights two matters which appear to have undermined the good governance of Taiwan Biobank in its early phases, and the general satisfaction with its development (though they cannot be said to have derailed its development). The first relates to its handling of ethnicity, including the special requirements that it imposes with respect to obtaining participant consent, and the second relates to the transparency (and accountability) around the undertaking's governance. These two matters are addressed in more detail in the sections that follow.

\section{Mishandled matter 1: Foregrounding ethnicity and consent shortfalls}

\subsection{The problem with ethnicity}

The specific identification of ethnic groups generated public controversy that was entirely predictable given the difficulties experienced by previous ethnicitybased genomic research, and the historic exploitation of Taiwanese Aboriginals.

41 Editorial, supra n. 36; Wen-Tsong Chiou, "The Dilemma of Taiwan Biobank Management", available at http://www.tahr.org.tw/node/1763 (accessed 31 May 2017). 
With respect to previous difficulties, international genomics collaborations have given rise to concerns about the use of 'race' or 'ethnicity' in science, and to questions about the rights of indigenous peoples (relating to benefits entitlement and ownership of knowledge). Two projects that failed to survive their controversies are:

- The Human Genome Diversity Project (1992) involved researchers from North America and Europe seeking to identify discrepancies in the genetic makeup of humans from around the world. ${ }^{42}$ It called for samples from 500 of the world's 5,000 'races' with an emphasis on indigenous or isolated communities, including those threatened with extinction. It was felt that their isolation supported unique genetic characteristics that would contribute to understandings of the origin and migration of humans. Some 722 groups were selected (165 from Africa, 212 from Asia, 114 from South America, 101 from Oceania, 107 from North America, and 23 from Europe), but it was discontinued.

- The Genographic Project was a 5-year international collaboration intended to collect biological samples from 100,000 indigenous peoples for the purpose of identifying genetic markers to assist in genealogical and human migratory research. Approved by the University of Pennsylvania's IRB, it recruited some 18,000 participants by the time the Indigenous Peoples Council on Biocolonialism (IPCB) intervened. ${ }^{43}$ Several Taiwanese organisations participated in its petition, arguing that the

42 Leslie Roberts, "How to Sample the World's Genetic Diversity" (1992) 257 Science 1204-1205.

43 The remit of the IPCB is to assist indigenous peoples protect their genetic resources, knowledge, culture, and rights from the negative effects of biotechnology. For more, see http://www.ipcb.org/. 
benefits to subject populations were dwarfed by the risks, which included undermining identity and long-held beliefs if it were discovered that they are from somewhere other than they believed. This could undermine claims for sovereignty, land, and other legal rights. ${ }^{44}$ In response to pressure, including that from the UN Permanent Forum on Indigenous Issues, ethical approval for the project was revoked in 2006.

The continued use of ethnic difference in recruitment, and the influence that race has had on (genomic) science and clinical medicine, largely to negative effect, has been widely lamented. ${ }^{45}$ A study of 11 leading journals reported that 'race' was a confusing, imprecise, and flawed concept, and that ethnicity was also ambiguous and sometimes just a synonym for race; it concluded that these concepts are heterogeneous, contingent, and locally situated, and that there is a danger that their use could harden existing classifications, making them innate, immutable, and natural. ${ }^{46}$ Some argue that there is only one valid use of race in medical

44 Terence Tai and Wen-Tsong Chiou, "Equality and Community in Public Deliberation: Genetic Democracy in Taiwan", in Veikko Launis and Juha Räikkä (eds.), Genetic Democracy: Philosophical Perspectives (Munich: Springer, 2008) 105-120.

45 Kwame McKenzie and Natasha Crowcroft, "Describing Race, Ethnicity and Culture in Medical Research" (1996) 312 BMJ 1054; Alan Goodman, "Why Genes Don't Count (for Racial Differences in Health)" (2000) 90 American Journal of Public Health 1699-1702; Editorial, "Census, Race and Science" (2000) 24 Nature Genetics 97-98; Editorial, "Genes, Drugs and Race" (2001) 29 Nature Genetics 239-240; Morris Foster and Richard Sharp, "Race, Ethnicity and Genomics: Social Classifications as Proxies of Biological Heterogeneity" (2002) 12 Genome Research 844-850; Michael Root, "The Use of Race in Medicine as a Proxy for Genetic Difference" (2003) 70 Philosophy of Science 1173-1183; David Bevan, "Genes, Race and Drugs" (2004) 27 Clinical \& Investigative Medicine 5-6; Richard Cooper, Jay Kaufman, and Ryk Ward, "Race and Genomics" (2004) 348 New England Journal of Medicine 1166-1175; Editorial, "The Unexamined 'Caucasian'" (2004) 36 Nature Genetics 541; Troy Duster, "Race and Reification in Science" (2005) 307 Science 1050-1051; David Skinner, "Racialised Futures: Biologism and the Changing Politics of Identity" (2006) 36 Social Studies of Science 459-488; Sandra Lee, "Biobanks of a 'Racial Kind': Mining for Difference in the New Genetics" (2006) 40 Patterns of Prejudice 443-460.

46 Andrew Smart et al., "The Standardisation of Race and Ethnicity in Biomedical Editorials and UK Biobanks" (2008) 38 Social Studies of Science 407-423. 
research: that relating to disparities in access to healthcare. ${ }^{47}$ At base, while labelling and classifying are necessary social and scientific practices for ordering the world, the use of race and/or ethnicity for doing so is characterised by uncertainty because racial/ethnic categories are often negotiated (or imposed), contingent, and contextual.

The second factor dictating against use of ethnicity in Taiwan Biobank is the historical treatment of Taiwanese Aboriginals specifically. There are some 16 peoples in Taiwan who identify as Aboriginals and who have traditionally lived in close (and partially closed) social networks. Unlike Han-dominated society, their lives and activities are rooted in unique cultural and spiritual beliefs about, and relationships to, the land and other ethnic groups. And despite increasing 'Hanization', tribal unity - an intrinsic value deeply ingrained through received practices - and tribal decision-making persists, the latter being a ritualised process used to solve both every-day and extraordinary matters. And Taiwanese Aboriginals bear a long history of exploitation and mistreatment.

In the medical context, tensions have often arisen - and communication breakdowns and research failures have often been experienced - as a result of the attitudes traditionally adopted by researchers; they have too often seen themselves as bearers of knowledge and technologies that will improve the welfare of impoverished Aboriginal communities, or as extractors of knowledge from Aboriginal communities which could then be converted into more (commercially) useful forms. ${ }^{48}$ The knowledge and values of Aboriginals have

47 Cheryl Mwaria, "Rejecting Race as a Critical Marker of Human Biomedical Difference" (2009) 45 Houston Law Review 1483-1487. For an opposing view, see Michael Malinowski, "Respecting Rather than Reacting to Race in Basic Biomedical Research: A Response to Professors Caulfield and Mwaria" (2009) 45 Houston Law Review 1489-1492.

48 James Scott, Seeing Like a State: How Certain Schemes to Improve the Human Condition Have Failed (New Haven: Yale University Press, 1998); Linda Smith, Decolonizing Methodologies: Research and Indigenous Peoples (London: Zed Books, 1999). 
been devalued, and their economic status has been exploited to coerce cooperation. Additionally, public debates and consultations, when they have occurred, have been focused in urban areas, thereby discouraging Aboriginal involvement, or have relied on communication methods which neglect their traditional models and so marginalises them. The result is that Aboriginal rights have been threatened. The following has been reported:

...[R]esearchers often went to tribal villages to covertly collect blood samples under the guise of 'free health checks'. A news report even quoted a villager as saying that in just one year he gave blood eight times - meaning perhaps several times in his native tongue - for 'free health checks'. Moreover, the Bureau of Health Promotion has been offering indigenous elderly two physical examinations per year for free, but, lacking a sound monitoring procedure, this well-intentioned health policy has unfortunately made examinees vulnerable to surreptitious, unconsented extraction of more blood ... than is necessary for the proclaimed purposes. [E]ven today one still finds that the registration form of a major hospital in an east-coast county requires indigenous patients to fill in tribal origins of their parents and grandparents - something that is absolutely unnecessary for diagnostic or therapeutic purposes. ${ }^{49}$

Although there have been no formal complaints, there have been controversies. In the NSC-funded Kavalan Project, an interdisciplinary team of researchers sought to investigate migratory routes and origins of Taiwanese Kavalan. Participants provided family and ethnic histories and blood samples. A tribal elder expressed concern about the collection of blood, which is viewed as sacred,

49 Tai and Chiou, supra n. 44. 
so the researchers agreed to take saliva instead, obtaining 29 samples. ${ }^{50}$ But the Kavalan Development Association filed a formal request for the withdrawal of the project and a return of the samples, emphasising that the project should have been considered by the tribe as a whole. In April 2007, the samples were returned to the participants and they were disposed of in a public ceremony. ${ }^{51}$ As a result of all this, some Aboriginal communities - who often see themselves as oppressed minorities - have erected moratoriums on research within their territories. $^{52}$

\subsection{The law and current state-of-play}

Before the Government embarked on its legislative programme relating to biobanks, research, and privacy, the Indigenous Peoples Basic Law 2005 (Basic Law $)^{53}$ was in effect. Article 21 stipulates that when governments or private parties engage in research in indigenous peoples' regions, they must consult with, and obtain consent from, the peoples or tribes. As such, early and ongoing engagement (or consultation) with Aboriginal groups on Taiwan Biobank's development, investigative limits, and internal practices was warranted from the outset. And given that a Community Review Board system has been in place among some Aboriginal tribes for years, ${ }^{54}$ it is curious that neither Academia Sinica nor Taiwan Biobank operatives set the appropriate actions in motion.

50 Amy Lemke et al., "Public and Biobank Participant Attitudes Toward Genetic Research Participation and Data Sharing" (2010) 13 Public Health Genomics 368-377.

51 Yuan-Xiang Liu, “Discussing Ethics of Genetic Research Involving Indigenous Peoples: Concerning the Protection of Collective Rights" (2007) 24 Newsletter of Biotechnology \& Law 44-62; Shu-Mei Tang, Shang-Yung Yen et al., "The Protection of the Human Research Subject and Institutional Review Board" (2010) 17 Journal of Law and Medicine 1-12.

52 Iain Davidson-Hunt and R O'Flaherty, "Researchers, Indigenous Peoples, and Place-Based Learning Communities" (2010) 20 Society \& Natural Resources 291-305.

53 See http://law.moj.gov.tw/Eng/LawClass/LawAll.aspx?PCode=D0130003.

54 Lemke et al., supra n. 50. 
Quite separate from consultation, there also needs to be a mechanism for encouraging community deliberation around participation. Such would encourage Aboriginal communities to discuss concerns and desires relating to Taiwan Biobank before freeing their members to exercise their own autonomous judgment. Again, a mechanism for obtaining community consent, or of recognising and engaging with existing mechanisms, was not apparently discussed by Taiwan Biobank in the 2005-2012 period. And despite Aboriginals being a specified target group, there is little evidence of a context-specific approach to them ever having been taken.

Now the HBMA 2010 states that biobank custodians must act in compliance with medical and research ethics, including standards relating to the provision of information and the taking of consent. Article 6 states that participants shall be informed of related matters in a clearly comprehensible manner, and such matters shall be specified in an agreement of consent. Collection may only be undertaken after the participant's written consent is obtained. Article 7 describes the information which must be given to potential participants in support of consent. ${ }^{55}$ Article 8 gives participants the right to withdraw or change the scope of their consent, although circumstances are listed when this cannot be exercised. ${ }^{56}$

55 This includes: the identities of the sample collector and the biobank operator; reasons for recruitment; the sample collection methods; potential complications and risks associated with collection; type of health information that will be accessed and linked in the future; the expected purposes and duration of use of the samples; possible impacts of genetic information derived from samples on the participant and his/her relatives or an ethnic group; other reasonable risks or inconveniences; rights and benefits under the Act together with rights that are excluded by the Act; the mechanism in place to safeguard privacy and other rights; the operator's organizational structure and operating principles; relevant regulations governing biobanks; and anticipated commercial applications.

56 Although Article 9 empowers custodians to continue to store and use samples and data after a participant's death or incapacity, except as otherwise agreed. 
The HSRA 2011 also captures biobank activities (Article 4), stipulating that all projects must be reviewed by the research entity's IRB (Article 5). Through Articles 12-14, it also requires consent to be obtained from participants, though where the HBMA 2010 allows for general consent, ${ }^{57}$ the HSRA 2011 requires more specific consent. Article 15 states that, where the research involves indigenous people, there shall additionally be consultations to obtain the consent of the indigenous group. The Central Council of Indigenous Peoples shall determine the consultation process, as well as determine the consent needs and any uses and commercial benefits. The related Regulations on Informed Consent for Research Involving Indigenous People, passed on 31 December 2015, also clearly mandates group consent for Aboriginals.

All told, then, the propriety of Taiwan Biobank taking different social and cultural contexts or perspectives into account when designing its recruitment and consent strategies, processes, and forms, and making room for alternative practices around consent, is well-founded on the evidence of the Project, and well supported by the legislation that both pre-dated its activities and was adopted during them. So what has Taiwan Biobank done? Now, it has removed references to ethnic groups from its website. Further, the website offers no information as to whether Aboriginals have been or are being recruited. It shows only a single consent form, and none of the EGC Meeting Reports posted since 2015 say anything about Aboriginal recruitment or consent.

57 Fan, Hung and Yeh, supra n. 5. 


\section{Mishandled matter 2: No governance framework communicated}

\subsection{General opaqueness}

The second matter highlighted by Taiwan Biobank's fraught evolution is the absence of any sound governance framework being in place during the feasibility phases, when thousands of samples were being collected. The project was centred in Academia Sinica, and the Protocol was loosely based on UK Biobank, both seemingly salutary foundations, but no identifiable governance framework seems to have been in the proponents' minds when they undertook their Pilot and Preparatory studies. Even if a framework was within their minds, no effort seems to have been made to open lines of communication with communities of interest so that they could understand it and influence what it might look like. There was no programme of wider engagement/participation, and when actors raised concerns, as described above, they appear to have been ignored, and requests for information were denied.

This absence of wide participation undermined Taiwan Biobank's ability to anticipate or respond to critical social, ethical, and legal concerns, including those around ethnicity and management. Again, the negative consequences of this opaqueness and lack of responsiveness was entirely predictable, and there existed examples of the positive outcomes of open engagement (not least in the form of UK Biobank, which Taiwan Biobank purported to draw on). ${ }^{58}$ Already

58 Graeme Laurie, "Role of the UK Biobank Ethics and Governance Council” (2009) 374 Lancet 1676; Graeme Laurie, Ann Bruce, and Catherine Lyall, "The Roles of Values and Interests in the Governance of the Life Sciences: Learning Lessons from the "Ethics+" Approach of UK Biobank" in Catherine Lyall, Theo Papaioannou and James Smith (eds.), The Limits to Governance (Routledge: London, 2009) 51-77; Shawn Harmon, Graeme Laurie and Gill Haddow, “Governing Risk, Engaging Publics and Engendering Trust: New Horizons for 
science democracy was much debated and the notion of 'research integrity' was growing in importance in Europe. European policymaking has since advanced the idea of 'responsible research and innovation' (RRI), which evolved out of responses to previous technological mishaps, the rise of increasingly controversial innovations, and ongoing discussions about integrity in contexts of ignorance and uncertainty. ${ }^{59}$ Indeed, genomics and biobanking was one of the instigators of RRI, ${ }^{60}$ which emphasises reflexive, adaptive, and anticipatory governance, ${ }^{61}$ and strives for a more democratic and equitable science/society relationship, one that is deliberative, cooperative, and inclusive. ${ }^{62}$

All told, RRI calls for a comprehensive approach to research whereby all stakeholders can, at an early stage, develop insight into the social needs to which research ought to be directed, the range of options appropriate to a problem, and the consequences of research outcomes, and use this information to design protocols, products, and services. ${ }^{63}$ It necessitates engaging actors in

Law and Social Science" (2013) 40 Science and Public Policy 25-33.

59 Barbara Adam and Chris Groves, "Futures Tended: Care and Future-Oriented Responsibility" (2011) 31 Bulletin of Science, Technology \& Society 17-27; René von Schomberg (ed.), Toward Responsible Research and Innovation in the ICTs and Security Technologies Fields (Brussels: European Commission, 2011); Hilary Sutcliffe, A Report on Responsible Research and Innovation (2011), available at https://ec.europa.eu/research/sciencesociety/document library/pdf 06/rri-report-hilary-sutcliffe en.pdf (accessed 2 August 2018).

60 Kieran O'Doherty et al., "Explosives, Genomics, and the Environment: Conducting Public Deliberation on Topics of Complex Science and Social Controversy" (2013) SAGE Open 1-17.

61 Richard Owen and Nicola Goldberg, "Responsible Innovation: A Pilot Study with the UK Engineering and Physical Sciences Research Council" (2010) 30 Risk Analysis 1699-1707; Richard Owen, Phil Macnaghten, and Jack Stilgoe, "Responsible Research and Innovation: From Science in Society to Science for Society, with Society" (2012) 39 Science \& Public Policy 751-760; Bernd Stahl, "Responsible Research and Innovation: The Role of Privacy in an Emerging Framework" (2013) 40 Science \& Public Policy 708-716.

62 Michiel van Oudheusden, 'Where Are The Politics in Responsible Innovation? European Governance, Technology Assessment, and Beyond' (2014) 1 Journal of Responsible Innovation 67-86.

63 EC Expert Group on Dealing with Ethical and Regulatory Challenges of International Biobank Research, Biobanks for Europe: A Challenge for Governance (Brussels: EC, 2012); EC 
participatory practices at all stages of research and all levels of governance, from agenda setting, to design and implementation, to evaluation. This was obviously not done by Taiwan Biobank: it grounded its original protocol on contested identities; it refused to make public processes; it made findings of feasibility without making the targets it set; and it founded an EGC but amended its protocol on its own, and then quarrelled with other relevant regulators/overseers about its authority and procedures.

\subsection{The law and current state-of-play}

As noted above, confronted with ongoing social dissatisfaction - not necessarily with the bank per se, but with how it was being developed/managed - the Government embarked on an extensive legislative programme. Foremost is the HBMA 2010, which applies to all biobanks established for research (as opposed to forensic banks). ${ }^{64}$

With respect to stewardship or governance, Article 5 HBMA 2010 states that operators shall establish an IRB of 9-15 members to review and supervise management matters. In the case of Taiwan Biobank, this is the EGC, and it has been argued that the EGC is at the centre of Taiwan Biobank's management. ${ }^{65}$ Operators must act in compliance with medical and research ethics (Article 6). Under Article 15, samples shall not be exported, though derived lines can be, and approval of the Competent Authority is needed. Articles 16-17 sate that research

Expert Group on the State of the Art in Europe on Responsible Research and Innovation, Options for Strengthening Responsible Research and Innovation (Brussels: EC, 2013); EU, Horizon 2020: Responsible Research and Innovation (2017), available at http://ec.europa.eu/programmes/horizon2020/en/h2020-section/responsible-researchinnovation (accessed 7 March 2017).

64 In addition to Taiwan Biobank, there are now some 25 biobanks approved by the MOHW.

65 Fan, Hung and Yeh, supra n. 5. 
uses must be authorised (by the EGC), and the principles of fairness and equality shall apply to access. Under Article 4, the Competent Authority can make rules and regulations to govern matters such as user qualifications, access procedures and conditions, review standards, biobank inspections, and other matters of compliance. ${ }^{66}$

It is unclear at this time how close or effective the EGC's oversight of Taiwan Biobank's operations is or might become; the Protocol amendment debacle does not illustrate an openly communicative setting, either between the bank and the EGC, or with the other key actors like Academia Sinica's IRB and the MOHW. The formation of the EGC does not extinguish the IRB's role as the IRB of the host institution, ${ }^{67}$ but the two bodies need to clarify their respective roles, and communication between them does not seem to be regularised, or even particularly positive. ${ }^{68}$ The erasure of the ethnicity foundation without comment or development of culture-sensitive recruitment procedures is also worrying, and not at all in keeping with the openness and discursiveness currently favoured (by policy approaches like RRI).

Article 21 HBMA 2010 states that any profits received by operators that are derived from commercial use of banked materials shall be given back to the specific population groups to which the respective participants belong. It is unclear whether Taiwan Biobank has a general benefit-sharing plan in place, or, more appropriately, any specific ones relating to Aboriginal participants. Article 5 HBMA 2010 states that any matters related to the application of data contained

66 The Administrative Regulations on the Establishment of Human Biobanks were adopted in 2011: http://law.moj.gov.tw/Eng/LawClass/LawAll.aspx?PCode=L0020173.

67 Chien-Te Fan and Wan-Hsuan Lin, "The Relationship of Human Biobank Management Act and Human Subject Research Act in Taiwan" (2013) 215 Taiwan Law Review 5-16.

68 Shu-Mei Tang and Shang-Yung Yen, "Development of Taiwan Biobank: Ethical, Legal, and Social Implications (ELSI)" (2017) 6 Bio-Industry Technology Management Review 71-90. 
in the bank shall be drafted as a plan and submitted to the IRB for approval, after which it must be submitted to the Competent Authority who will invite legal experts, social workers, and other disinterested community members to review it before final approval. Presumably such a plan has been submitted to the MOHW, though this is not clear.

Any loss or theft of, or tampering with, samples, data, or information must be investigated immediately and reported to both the Competent Authority and to affected participants (Article 11). Articles 12-13 state that individuals engaged in collecting, processing, storing, or using samples and data shall maintain confidences, and the operator shall disclose rules on information management, which must be submitted to the Competent Authority after approval by the REC. In support of this, the Human Biobank Information Security Regulations 2010 were adopted. The Regulations focus on training, outsourcing, security systems and linkage management, and access to systems, but it is argued that uncertainty remains around the security measures that might be adopted to prevent unauthorised access and leakage. ${ }^{69}$ Article 18 stipulates that samples and data must be encoded, encrypted, delinked, or transformed so that the participant's identity cannot be determined. But again, the operation of this in the context of sharing across banks (which is now a central stream of activity for Taiwan Biobank with the addition of the hospital samples) is uncertain. It would seem that the HBMA 2010 forbids such activity.

As demonstrated above, despite the comprehensive regulatory framework that has now been erected in relation to biobanks, there remains much uncertainty around the governance of Taiwan Biobank, not least in relation to data management. More importantly, there seems to be a persistent reluctance

69 Fan, Hung and Yeh, supra n. 5; Chien-Te Fan and Tsung-Hsien Liang, "Addressing the Controversies Raised on Taiwan Biobank" (2007) 91 Taiwan Law Review 48-59. 
to engage in discourses with the public on these issues, and on governance matters more generally. And the laws that have been adopted have neglected to impose any sort of mandated participatory activities.

\section{Conclusions: Taiwan Biobank - A cautionary tale}

Taiwan Biobank is generally supported as a national project, but it has been criticised with regard to its operation to date. We suggest that the foregrounding of ethnicity and the absence of transparency have caused particular concerns that have not been well managed. If ethnicity was felt to be important, it needed to be more clearly delineated, more openly discussed, and more appropriately managed with respect to specific and bespoke recruitment mechanisms and governance processes. Also, given the general trend over the last 20 years with respect to science communication and the importance and value of healthy science-society partnerships, a much more open and participative approach to development, feasibility-testing, and stewardship was warranted.

With respect to recommendations, we argue that the evidence suggests that Taiwan Biobank must increase and improve its communication with stakeholders, including specified ethnic groups (whether as participants or as members of the broader public) if it is to maintain and finally secure legitimacy, and achieve some level of justifiable public trust. Taiwan Biobank not only needs concrete standards, but a means of making those standards understood. Related to this, the EGC should take steps to design ethically and legally sound recruitment practices that take into account cultural diversity (and the demands of legally protected groups). These practices should be clearly identified on the Taiwan Biobank website, and complied with by recruiters. Third, there is also significant work to be done with respect to privacy, and ensuring that Taiwan Biobank achieves its maximum utility through collaboration with researchers 
and other banks. Indeed, collaboration between Taiwan Biobank and other banks is just now starting, and this demands much more consistent and proactive engagement and rigorous public scrutiny than has exemplified to date. As part of this, Taiwan Biobank must come to grips with its multi-party supervisory situation (i.e., the demands of its oversight by the EGC, the IRB, and the MOHW must be determined and communicated so that errors are avoided and the process does not become too burdensome).

Our take-home message is that the development of Taiwan Biobank must be viewed as a cautionary tale, an example of how not to develop a national population genetic biobank. Its survival can be characterised as a product of the autocratic approach adopted by its proponents, and any adjustments toward openness or sensitivity might surely be a credit to the perseverance of the academic and civil society actors who have worked so hard to insinuate some level of scrutiny into the governance of the undertaking. 